\title{
DEVELOPMENT OF A BIM INFRASTRUCTURE WORKFLOW ADAPTED TO FACILITIES OF LAND SUBDIVISION PROJECTS IN MOROCCO
}

\author{
M. Bouziani ${ }^{1 *}$, H. Mouatassim² ${ }^{2}$ K. Fadl ${ }^{1}$, H. Nouari ${ }^{1}$ \\ ${ }^{1}$ School of Geomatic Sciences and Surveying Engineering, IAV Hassan II, Rabat, Morocco - (m.bouziani@iav.ac.ma) \\ ${ }^{2}$ Bureau d'Etudes Techniques Mouatassim, Casablanca, Morocco
}

KEY WORDS: BIM, Infrastructure, BIM Workflow, BIM Process, Land Subdivision, Digital Model

\begin{abstract}
:
Land subdivision represents a complex procedure which leads to the construction of a set of buildings and utilities necessary for the viability of the project: Roads, sewerage network, water network, electricity network and telecommunication networks. The techniques adopted so far to carry out land subdivision projects in Morocco have certain limitations. Several stakeholders are necessary for the realization of a land subdivision and many 2D plans and documents are used. These plans and documents are independently produced and carried out by the various trades involved in the project. If a change is made to one element of the project, which often happens, several documents and plans are affected and must be updated. This can be a source of errors and conflicts and can lead to an increase in the time and cost of the hall project. This study proposes the development of a Building Information Modelling (BIM) infrastructure workflow adapted to land subdivision projects in Morocco. The integration of BIM in this type of project is an innovation in the Moroccan context. It will improve the design, simplify communication and collaboration between the various stakeholders and facilitate the management and the monitoring of the project. The resulting digital BIM model can be used to produce 2D and 3D construction plans, take measurements and plan work. It constitutes the basic platform to perform calculations and simulations at any stage of the infrastructure life cycle and to detect and resolve interferences in a collaborative environment.
\end{abstract}

\section{INTRODUCTION}

Currently, streets and facilities of land subdivision projects in Morocco are treated with representations through 2D plans and rarely in 3D. These projects regularly present technical issues that are difficult to understand using only $2 \mathrm{D}$ plans. It is therefore essential to evaluate the use of 3D representations and BIM (Building Information Modeling).

BIM is a working method using an intelligent 3D digital model as a reliable basis from design to operation phases. It facilitates information exchanges and collaboration between the different stakeholders in a construction project by defining the responsibilities, periods and limits of intervention of each.

The digital BIM model is made up of objects defined by a multitude of geometric, technical, financial, functional, time, cost and energy characteristics. It is produced by the designer using BIM solutions appropriate to the nature of the project. It is then enriched and used by the various collaborators of the project.

BIM has continued to develop and is used in different phases of the life cycle of a growing number of buildings and infrastructures. Tools employed allow all the elements necessary for this collaborative working method to be integrated.

Although it was recently adopted for infrastructure projects, BIM has proven great potential. It offers the ability to manage the entire infrastructure life cycle from planning and design to construction and maintenance by providing a comprehensive visual database of the project. Several studies have been carried out (Abbondatia et al., 2020; Ait Lamallam et al., 2019; Arnaud,
2019; Chong et al., 2016; Costin et al., 2018; Fernando et al., 2014; Joos et al., 2017, Olfat et al. 2019).

BIM markets are booming, mainly for buildings. For infrastructure construction, a notable evolution has been recorded in recent years with a growing adoption of BIM process. In addition, several tools and digital solutions for the design and operation of the digital BIM models adapted to infrastructures (roads, bridges, networks, etc.) are currently available and have powerful options adapted to the different phases of the life cycle of an infrastructure.

In this context, land subdivision represents a complex procedure which leads to the construction of a set of buildings and utilities necessary for the viability of the project: streets, sewerage network, water network, electricity network and telecommunication networks. The techniques adopted so far to carry out land subdivision projects in Morocco have many limitations. Furthermore, several stakeholders are necessary for the realization of a land subdivision project and many $2 \mathrm{D}$ plans and documents are used.

The integration of BIM in this type of project is an innovation in the Moroccan context. It will improve design, construction and operation processes. It will also simplify communication and collaboration between the various stakeholders, reduce time and costs and facilitate the management and the monitoring of the project. The resulting digital BIM model can be used to produce $2 \mathrm{D}$ and $3 \mathrm{D}$ construction plans, take measurements and plan work. It constitutes the basic platform to perform calculations and simulations at any stage of the infrastructure life cycle and to detect and resolve interferences in a collaborative environment. The adoption of BIM supports the

\footnotetext{
* Corresponding author
} 
creation of equipment and arrangements consistent with the urban environment present in the vicinity of the subdivision project.

This study proposes to develop a BIM infrastructure workflow adapted to facilities of land subdivision projects in Morocco. In the following sections, we will present the study area, the proposed workflow and the tools used for validation. Then, we will give and discuss results examples using the BIM model generated. The article ends with the conclusion. This study was conducted in the frame of collaboration between the School of Geomatic Sciences and Surveying Engineering, IAV Hassan II, and BET Mouatassim Company.

\section{MATERIAL AND METHOD}

\subsection{Study area}

The case study chosen to carry out this work consists of a residential subdivision project which is underway located in the urban perimeter of the Hay Hassani district in Casablanca, Morocco. The project is divided into twenty-three lots and comprises three streets and four types of utilities: sewerage, water, electricity and telecommunication. The following figure presents the location of the project.

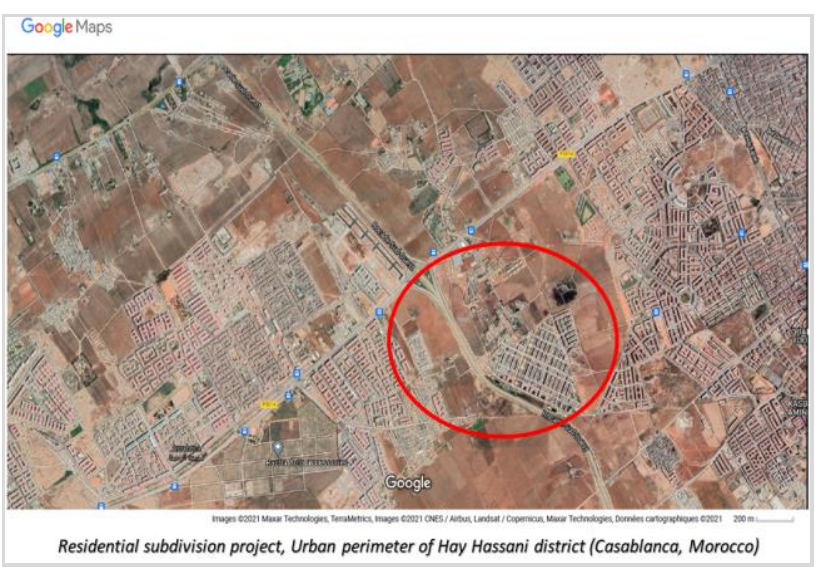

Figure 1. Location of the study area (Google Maps, 2021)

To carry out this study, we have a set of 2D plans and data about the study area provided by the design office responsible for the monitoring the project.

\subsection{Methodology}

The following figure presents the methodological flowchart comprising the main steps that we followed in order to optimize land subdivision projects by integrating the BIM process:

The methodology followed in this study to propose a BIM infrastructure workflow is made up of three main phases: planning, design and operation.

In the planning phase, we carried out a unification of the work templates as well as a modeling of the BIM process in line with the study and work phase protocols. All the necessary data was collected during this phase: Digital Terrain Model (DTM), design standards, dimensions and specification of the facilities.

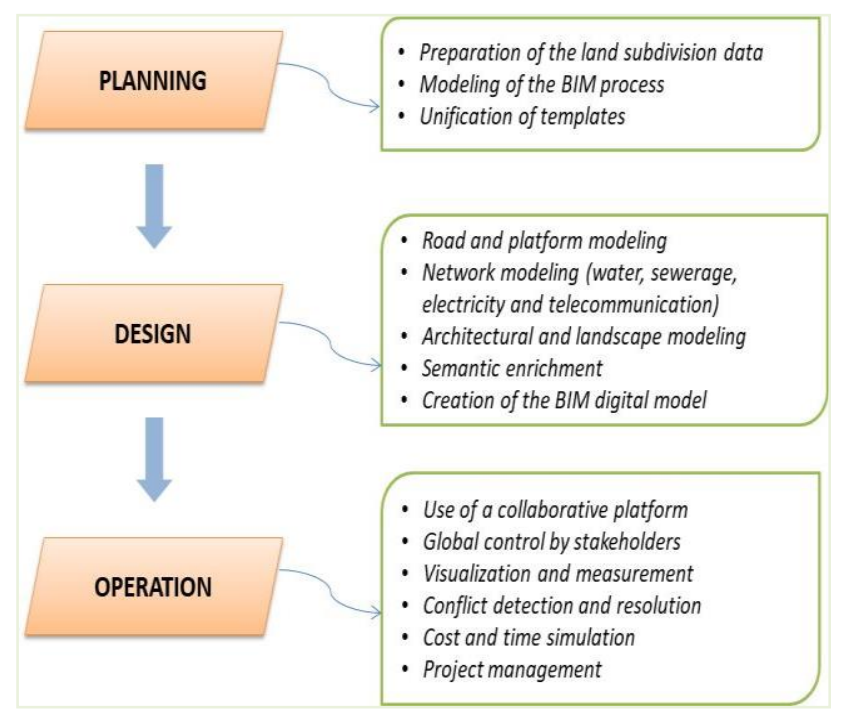

Figure 2. Methodology

The design phase consists of carrying out the detailed design of streets, sewerage, drinking water, electricity and telecommunication networks. Subsequently, an architectural and landscape modeling of the project was carried out in order to be able to visualize the project in its environment. Finally, the overall digital model was obtained by assembling all the design elements to better visualize the entire project.

In the operation phase, we used the DTM obtained to realize quantitative calculation, creation of site execution plans, detection and resolution of interferences, time (4D) and cost (5D) simulations, documentation and finally the creation of the project database.

\subsection{BIM Softwares used}

In order to validate the proposed BIM workflow, we used the following suite of software solutions: Civil 3D, Infraworks, Navisworks and BIM 360 platform.

3D modeling of the subdivision platform, streets and utilities is carried out on Civil 3D. It is produced from the DTM and the design data of the project. After carrying out the design in Civil $3 \mathrm{D}$, we export the digital model of the project to Infraworks to be able to improve the visual and communicative aspect.

Thus, an architectural model is designed to allow the visualization of the integration of the project in its environment. Model Builder on Infraworks was used. This tool allows the creation of models of a specific area of interest. It uses the cloud to find data layers before generating a model for the study area. OpenStreetMap data and satellite images from Microsoft Bing Maps are used and draped over the 3D model of the project. The resulting architectural model contains buildings, streets, facilities, streetlights and other realistic objects of the project environment.

The last point to take into account is the landscape aspect by integrating green spaces and plantations. This will ensure a better integration of the project in its environment. Infraworks software can manage these elements thanks to its library containing 3D landscape objects. 
When creating the different objects, we combine modeling by geometric and semantic attributes at the same time. The digital model obtained can be qualified as a BIM infrastructure model. The choice of attributes is always conditioned by the objective or the future use of the developed BIM model. Since we aimed at the realization of street and utilities, our choice of attributes was oriented to fulfill this goal.

After importing and assembling all the components of the BIM digital model it is possible to carry out a global check which ensures the quality of the modeling. For a correct incorporation of the all produced elements, we georeferenced the project in the same coordinate system and in the same projection. Infraworks provides tools to create presentations for better visualization.

Then, the supplied model was imported into Navisworks to produce summaries as well as simulations to improve the operational efficiency, time and cost assessments. The entire process was made possible under the BIM 360 platform to allow collaboration between the different trades involved during the project life cycle.

The interoperability of workflows between the used softwares is one of the key factors for successful integration. The ability to work on a design project, easily switching from one product to another, allows each design to benefit from the respective strengths of the other modules. The combination of many softwares allows rapid conceptualization and improvement as the design progresses as well as bringing the industry closer to the ideal of true BIM workflows.

\section{APPLICATION}

\subsection{Visualisation}

We first performed a preliminary visualization with Infraworks software. This allowed us to integrate data from various sources in a realistic environment. This will offer better visualization of the subdivision development integrated in its environment with a visual rendering of high quality.

The following figure shows views of the final result of the BIM digital model of the complete subdivision project. With that result, we have a better overall understanding of the project.
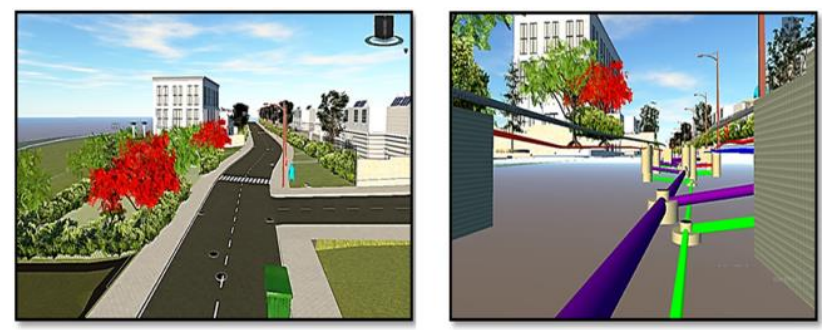

Figure 3. BIM digital Model of the land subdivision Project

\subsection{Collaboration}

The 3D digital model allows collaboration between the different stakeholders of the project. Collaborators have their own level of access and participation in the platform. The following figure shows streets and utilities model loaded and viewed on the BIM 360 collaboration platform.

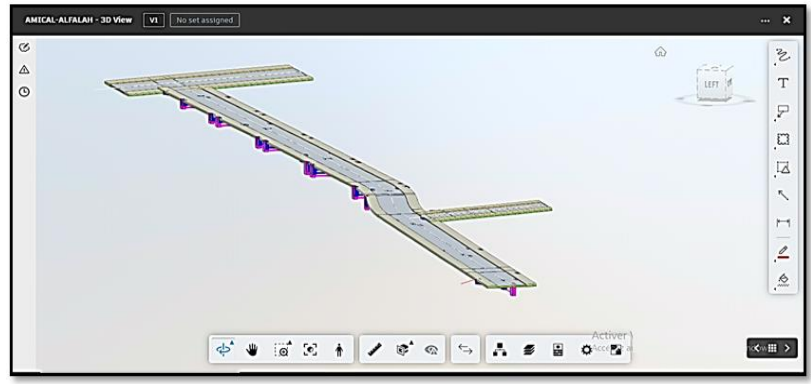

Figure 4. BIM Model on the collaborative plateform BIM360

The functionalities of the platform make it possible to control project elements, display the model, take measurements and display objects characteristics. The following figure illustrates a measurement operation taken on the model to verify the dimensions of the street.

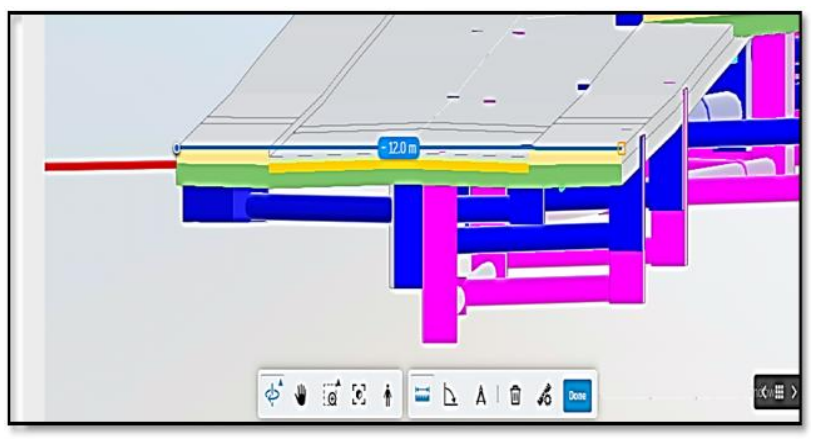

Figure 5. Measurements on the BIM Model

During the collaborative work around BIM digital model, problems can be pointed out. Responsible are then assigned to solve them. The following figure represents an example of signaling problems on the BIM model.

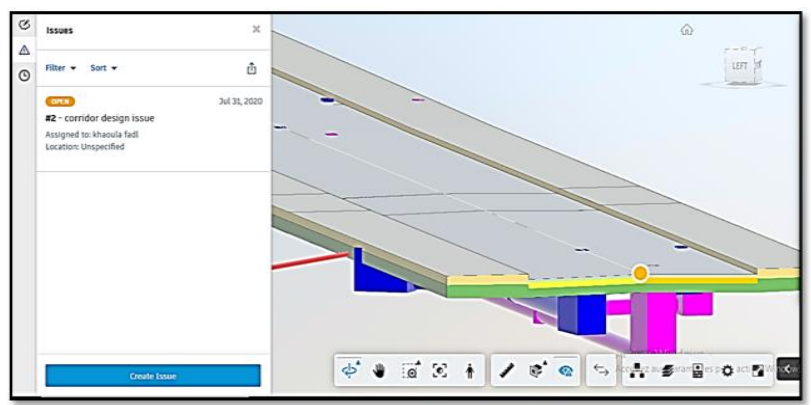

Figure 6. Problem detection on the BIM model

BIM 360 platform allows easy access to the model. In addition to the possibility of sending comments and reporting problems, it also allows a wide choice of data formats to be shared.

\subsection{Conflict Detection}

After integrating a set of rules and parameters specific to utilities installations, conflict detection analysis can be activated. The results are then displayed and checked interactively. A list of conflicts and controls are presented to manage them. The following figure represents an example of conflicts detected between drinking water network and 
electricity network. A report can be configured and produced covering all conflict results detected during the analysis.

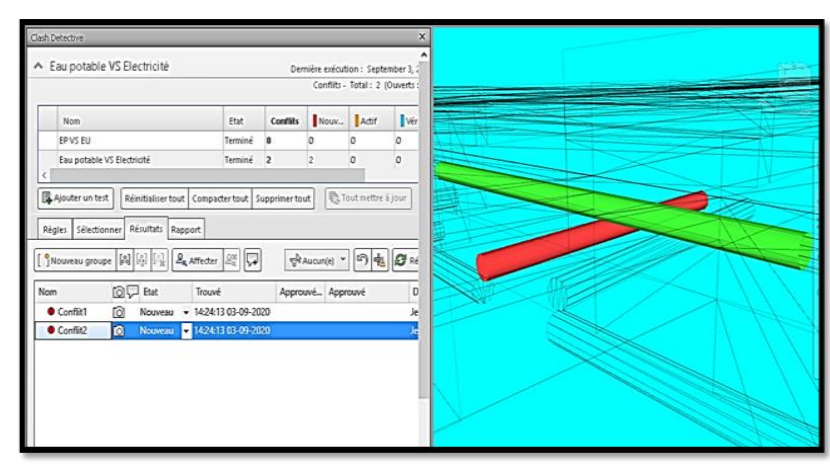

Figure 7. Clash detection on Navisworks

\subsection{Discussion}

The workflow proposed made it possible to demonstrate the advantages of BIM infrastructure applied to land subdivision projects.

The digital model obtained has been exploited to better design, build and operate the utilities of the project. Applications include visualization, communication, conflict detection, monitoring of the phases of the project, simulations of time and cost. Thus, in this study, we obtained a 5D BIM dimension.

The model was also used to ensure a smarter collaborative process between the various stakeholders in the project. We therefore arrive at a maturity level 3. A single model is stored and centralized in a collaborative platform accessible by all stakeholders.

In the absence of a specific BIM solution adapted for infrastructures, we combined in our study four Autodesk solutions into a BIM workflow for the completion of land subdivision projects in Morocco. Civil 3D is used in the design of roads and facility networks. Infraworks is more intended for the $3 \mathrm{D}$ visualization of the project inside its environment. Navisworks offers the possibilities of conflict detection as well as time and cost simulations. Finally BIM 360 is used as a collaboration platform.

During the experimentation, we faced a lack of interoperability between Civil 3D and Infraworks with regard to road layers. In our study we have been constrained also by several factors in particular: the need to have high-performance workstations, the lack information sharing between some collaborators, the absence of some data sources to further enrich the project by semantic information, and the scarcity of references for similar projects dealing with BIM for infrastructures.

For future studies, we will improve the workflow to be adapted for more complex projects. Additional data sources will be integrated, such as geotechnical and energy studies. Furthermore, we will assess the addition of detailed architectural design using Revit software and the creation of more complex objects using Inventor software.

\section{CONCLUSION}

This study focused on the development of a BIM infrastructure workflow adapted to land subdivision projects in Morocco. We have proposed a methodology composed of three phases: planning, design and finally operation. The BIM workflow has been validated with solutions from the Autodesk suite.

The proposed workflow can be used as a guide for the realization of infrastructure projects of the same type. The adoption of BIM processes allows bringing many advantages in all phases of the subdivision project:

- Improve the quality of the design and provide a better visual representation of the infrastructure.

- Simplify communication and improve collaboration between the different stakeholders.

- Help identify and resolve conflicts during the design and construction phases.

- Reduce conflicts and coordination problems on the site.

- Improve strategic planning and management of project tasks.

- Control the deadlines and costs of the project.

- Improve the planning of maintenance missions in the maintenance phase.

Further work is planned to integrate additional data sources and improve the workflow to be adapted to more complex projects.

\section{REFERENCES}

Ait-Lamallam S., Sebari I., Yaagoubi R., Doukari O., 2019. Vers une extension du Building Information Modeling aux projets d'infrastructure routière: Cas d'étude d'un échangeur autoroutier au Maroc. Revue Marocaine des Sciences Agronomiques et Vétérinaires. Vol. 9, pp. 609-617.

Abbondatia F., Biancardob S., Palazzob S., Capaldob F., Viscione N., 2020. I-BIM for existing airport infrastructures. AIIT 2nd International Congress on Transport Infrastructure and Systems in a changing world, Naples, pp 596-603.

Arnaud M., 2019. L'apport du développement d'outils BIM au sein des projets d'infrastructures. Mémoire pour l'obtention du le diplôme d'ingénieur Géomètre et Topographe, ESGT : diplôme d'ingénieur CNAM, Le Mans, 67p.

Chong H., Lopez R., Wang J., Wang X., Zhao Z., 2016. Comparative analysis on the adoption and use of BIM in road infrastructure projects. J. Manag. Eng. 32 (6) pp.1-13.

Costin, A., Adibfar, A., Hu, H.S., Chen, S., 2018. Building Information Modeling (BIM) for transportation infrastructure Literature review, applications, challenges, and recommendations. Automation in Construction, 94, pp.257-281.

Fernando G., Bañuelos B., Haibo C., 2014. The Implementation of Building Information Modelling in the United Kingdom by the Transport Industry. The 9th International Conference on Traffic \& Transportation Studies (ICTTS'2014), United Kingdom, pp.510-520. 
JOOS J., Charles J., 2017. Le BIM pour les infrastructures, Etat des lieux et problématique. Cerema, Rapport de recherche, Isle D'Abeau Cedex, 26p.

Olfat H., Atazadeh B., Shojaei D., Rajabifard A., 2019. The Feasibility of a BIM-Driven Approach to Support Building Subdivision Workflows - Case Study of Victoria, Australia. ISPRS Int. J. Geo-Inf. 2019, 8(11), 499. 